\title{
Organic Coatings with Low IR Emission
}

\author{
CRISTIANA EPURE ${ }^{1}$, VIOREL TIGANESCU ${ }^{2}$, TEODORA ZECHERU ${ }^{1,3}$, GABRIEL EPURE $^{1}$, \\ OVIDIU IORGA ${ }^{1 *}$, ANDREI SCHIOPU ${ }^{1}$, MIHAIL MUNTEANU ${ }^{1}$, ALEXANDRU MARIN ${ }^{1}$, \\ RALUCA GINGHINA ${ }^{1}$, DANIEL TURCANU ${ }^{4}$, CORNEL TODIRICA $^{3,4}$ \\ ${ }^{1}$ Scientific Research Center for CBRN Defense and Ecology, 225 Sos. Oltenitei, 041309, Bucharest, Romania \\ ${ }^{2}$ Military Equipment and Technologies Research Agency, 16 Aeroportului Str., 077025, Clinceni, Romania \\ ${ }^{3}$ General Directorate for Armaments, 9-11 Drumul Taberei, 061418, Bucharest, Romania \\ ${ }^{4}$ Center for Test-Evaluation and Scientific Research for Armaments, 16 Aeroportului Str., 077025, Clinceni, Romania
}

\begin{abstract}
A series of methods were employed to assess the performances of advanced coating materials based on components that can modify the spectral parameters of the surfaces on which these materials are applied in order to obtain passive military camouflage. Powder materials with high infrared (IR) reflectance were used to obtain this type of coatings, which also ingrain in their structure a significant volume of air that allow limitation of the radiative heat transfer of the coated source. The components were embedded in a polyurethane matrix, which facilitated the coating process on different surfaces. The bicomponent polyurethane-based binder used within the different composition tested is transparent to incident IR radiation, has no organic solvents, is highly flexible and possesses remarkable physical, chemical and mechanical properties: high surface adhesion, high flexibility and resistance against a number of chemical agents and external factors with destructive effect. The efficiency of these composite materials was further demonstrated by analyzing the thermal images of different objects.
\end{abstract}

Keywords: passive camouflage, glass microspheres, aerogel, polyurethane

\section{Introduction}

Polymer coatings characterized by complete or selective infrared (IR) reflectivity are employed in many research and industrial fields. E.g., paint or other architectural coatings are used to reflect the incident solar radiation or the heat radiation from inside, therefore obtaining thermal isolations that reduce energetic cost. Similarly, camouflage coatings reflect the IR radiation in the surrounding medium, thus delaying or preventing targeting and identification of strategic objectives. Military vehicles which are in operation can generate IR radiation from sources such as engines and exhaust plumes. The IR sensors of the thermal camera are capable of detecting the radiation with the wavelength between 700$1350 \mathrm{~nm}$ (near IR - NIR), 3-5 $\mu \mathrm{m}$ and 8-14 $\mu \mathrm{m}$ (thermal IR - TIR). Thermal imaging cameras measure the relative temperature between the source of radiation and the surrounding environment, identifying the object by its heat or IR signature (the object emitting the radiation has a different color versus the surrounding environment).

Thermal imaging cameras can detect objects by their emissivity, a parameter that characterizes the surface of the object. The emissivity of a material represents the efficiency with which the object radiates energy as thermal radiation and is the ratio of radiance from a surface sample to that of a black body surface at the same temperature; the value obtained is between 0 and 1 , and the emissivity of the black body is considered equal to 1 . Thus, by reducing the emissivity of a surface, the thermal signature of the object is reduced efficiently. Moreover, it was demonstrated that a surface with an emissivity between 0.4-0.6 can produce an efficient camouflage [1].

In order to reduce the emissivity, the surface can be coated with a film forming material with solid particles that present a high IR reflectivity, a property which is directly influenced by the geometry, the powder materials particles dimensions and their concentration [2-4]. The binder must protect the particles against external aggressive factors during the entire period the object is coated and also must have a low absorbance, thus allowing the incident radiation to intersect with the solid particles [5].

*email: iorga_ovidiu@yahoo.com 
By employing additives in the composition (solvents, coalescing agents, tensio-active, anti-foaming, rheological agents, etc.), the emissivity increases by up to $10 \%$, therefore the composition should have a reduced number of this type of components.

Various types of binder compositions have been used over time in IR camouflage, such as: polyvinylidene fluoride, silicone resins, silica oligomers, polyurethane binders, epoxy binders, acrylic binders, vinyl binders, polyolefin binders and chlorinated polyolefins [5-8].

In this context, the present study aimed to investigate new polymer coatings formulas based on advanced materials used in a variety of industrial domains and to adapt them to military requirements.

\section{Materials and methods}

\subsection{Materials}

For the composite materials synthesis, the following components were employed as such: silicaaerogels Aerogel IC3100 and Aerogel IC3110 (>95 wt\% purity), purchased from Cabot Corporation; K1 and K20 glass microspheres (>98 wt\% purity), obtained from 3M; Setathane D1160 acryl-hydroxy polyol without solvent (>95 wt\% purity), provided from NUPLEX; aromatic polyisocyanate based on diphenylamine diisocyanates without solvent, Desmodur VL ( $>95 \mathrm{wt} \%$ purity), acquired from COVESTRO.

The chemical compositions of the tested samples are presented in Table 1 (PU - tow component polyurethane binder: component 1 - polyol and component 2 - polyisocyanate).

Table 1. The polymer coating composition

\begin{tabular}{|c|c|c|c|c|c|}
\hline No. & PU, wt\% & Aerogel IC3100, wt\% & Aerogel IC3110, wt\% & Microsphere K1, wt\% & Microsphere K20, wt\% \\
\hline Sample 1 & 100 & - & - & - & - \\
\hline Sample 2 & 95 & 5 & - & - & - \\
\hline Sample 3 & 95 & - & 5 & - & - \\
\hline Sample 4 & 95 & - & - & 5 & - \\
\hline Sample 5 & 95 & - & - & - & 5 \\
\hline
\end{tabular}

\subsection{Manufacturing methods}

In the first step, component 1 of the polymer coating is prepared by embedding this powder material (aerogel/glass microspheres) under slow stirring at room temperature. $15 \mathrm{~min}$ before applying the product, the acrylic polyol (component 1) is mixed with the aromatic polyisocyanate (component 2). The performances of the low emission materials were tested by applying the composition on polyethylene foil in order to obtain 30x30x5 mm samples. After a minimum of 7 days, the samples were subjected to IR testing for evaluating the spectral performances.

\subsection{Analysis methods}

Powder materials are materials that influence the spectral properties of the polymer coating. The silica ratio content in the powder material reduces considerably the material surface emissivity due to its high reflectance value, which is over 90\% [9] when compared with the surrounding environment.

Silica-based aerogels are powder materials obtained by extracting the liquid component from silicagel and replacing it with gas [10-13]. The result is a solid powder material, with an extremely low density. The crystalline structure obtained has a high tendency to breakdown, given the presence of micropores, and therefore making this material difficult to produce. However, the chemical bonds in the dendritic microstructure are very strong. The constituting atoms are packed in clusters, which form a nanoporous tridimensional structure. Practically, ca. 97\% of silica-aerogel is air, efficient as thermoinsulator, given that the high volume of the air suppresses the heat transfer in the form of conduction and convection and also, the silicon dioxide has a reduced thermal conductivity and a high reflectance [14-18].

Glass microspheres are powder materials similar to silica-aerogels as they embed in their structure a relatively big volume of air, but this time in the interior of the silica microspheres, with a diameter 
between 1-1000 $\mu \mathrm{m}[19,20]$. They are used as thermal insulation materials in constructions due to their low thermal conductivity [21], or they are added in composite materials along with plastic materials, elastomers or other binders [22], given their low expansion thermal coefficient that prevents cracking. Due to the reduced compatibility between glass microspheres and binders, the former ones undergo a superficial treatment, which results in a greater wettability capacity [23-25].

Polyurethane binders are composed of a polyol - component 1 , and a polyisocyanate - component 2 [26]. The poly-addition reaction conducts to a stable tri-dimensional structure, indestructible in normal conditions, that can be used as a matrix together with other materials with special properties, in order to obtain performant coatings [27-30]. Depending on the chemical composition of the two components, the poly-addition reaction can be controlled in order to obtain the necessary properties (in terms of flexibility-elastomer, semi-rigid or rigid) of the polymer according to its final application. The flexible polymeric units have a length of 1000-2000 nm, and the rigid ones ca. $150 \mathrm{~nm}$ [31]. Polymeric elastomers are divided into three categories: liquid, millable rubber, thermoplastic. Only the millable rubber can be used for obtaining special composite materials, due to its capacity to embed fibrous powder materials or micro-porous materials that can lead towards the obtaining of special materials.

In order to evaluate the geometry of the particles and their spatial distribution, the powder materials were analyzed using a scanning electron microscope (SEM) with thermionic emitter VEGA II LMU Tescan, a general-purpose electronic microscope with thermionic emission electron gun with a wolfram filament, and coupled with an X-ray detector (EDX). The signal has been eliminated from the quantitative analysis.

In order to select the most efficient powder material which has the optimal spectral properties when applied to surfaces, a thermal emissivity analysis was made using the data recorded with a thermal imaging camera FLIR E8 (FLIR Systems OU, Estonia).

The thermal signature suppression capability of the applied composite material was analyzed using a FLIR SC4000HS thermo-imaging camera with the following characteristics: $3-5 \mu \mathrm{m}$ InSb detector, $320 \times 256$ pixels sensors resolution, 125 frames/s maximum acquisition rate, 10 to $90^{\circ} \mathrm{C}$ calibrated measuring domain, Ge lenses, $13 \mathrm{~mm}$ focal distance.

In order to reproduce real operational capacity, and to simulate a motor vehicle while operating a $600 \times 400 \times 400 \mathrm{~mm}$ parallelepiped metallic chamber was used. The chamber was heated from inside by a heat source coupled to a thermostat and a temperature sensor. The outer walls of the metallic chamber were coated with composite thermal-insulator material - Composition 4 , each wall with a different coating thickness: $8 \mathrm{~mm}, 17 \mathrm{~mm}$, and one wall has been maintained without any coating.

The enclosure obtained was analyzed with a thermal-imaging camera set at $2 \mathrm{~m}$ away. Tests were conducted for each individual wall. The measured data were transferred to a workstation model Panasonic CF-30 and further processed using ThermaCAM Researcher 2.9. software for radiometric measurements. For each trial, the temperature of the chamber was increased progressively, from 18 to $90^{\circ} \mathrm{C}$ and the data were recorded every $10 \mathrm{~s}$.

\section{Results and discussions}

Powders are materials that influence the spectral properties of a polymer coating. In this study, the silica was introduced in the powder material to form silica-based aerogels in order to reduce considerably the material surface emissivity due to its over $90 \%$ reflectance versus the surrounding environment [918]. Moreover, glass microspheres were employed due to their similarity with silica-aerogels, as they embed in their structure a relatively big volume of air, and also due to their low expansion thermal coefficient that prevents the formation of cracks and a greater wettability potential [19-25].

The morphology of the silica-aerogels and the microspheres was studied by SEM-EDX and is illustrated in Figures 1 and 2. The silica-aerogels present an irregular particles structure due to the mechanical milling, with dimensions ranging from $50 \mu \mathrm{m}$ to $700 \mu \mathrm{m}$ (Figure 1a). Their surface morphology is a direct effect of the manufacturing process and of the later erosion between the particles, resulting in the appearance shown in Figure $1 \mathrm{~b}$. The purity of the material determined by EDX is 
estimated to be over $99 \%$, eliminating the possibility that the material is contaminated with any compounds that could alter the thermal attenuation efficiency. The carbon specific signal present in the spectrogram originates from the carbon support used to fix the sample on the microscope stub (Figure 1c).

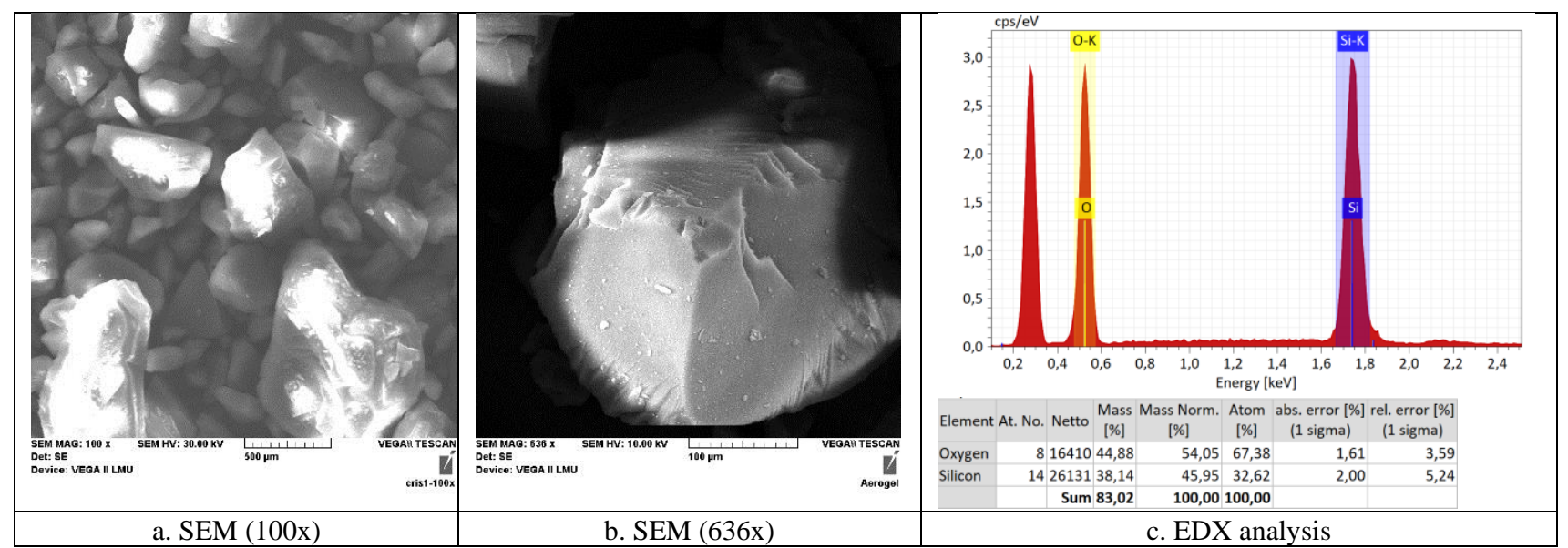

Figure 1. Morpho-structure of silica-aerogels

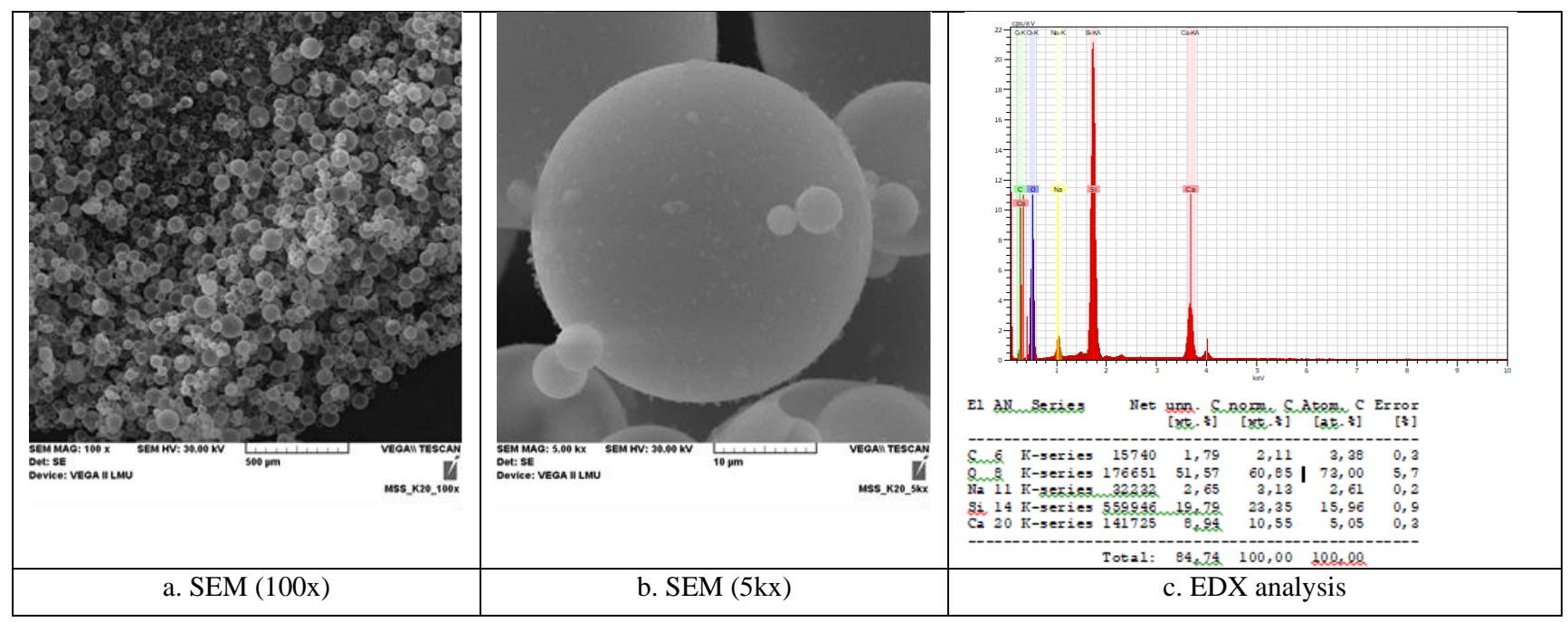

Figure 2. Morpho-structure of glass microspheres

The glass microspheres are hollow, as it can be noticed from the secondary electrons (SE) image (Figure 2a), where the projection of a sphere shows the density of the walls in contrast with the air filling of the microsphere. The particles are perfect spheres with dimensions ranging from several micrometers up to $100 \mu \mathrm{m}$. The morphology of the surface is irregular, including sub-micron size silica structures grafted on the microsphere exterior surface (Figure $2 b$ ). The EDX analysis shows a typical composition of a glass material ( $\mathrm{Si}, \mathrm{O}, \mathrm{Na}, \mathrm{Ca}$ ), while the carbon signal originates from the carbon band support used to fix the sample on the microscope stub (Figure 2c).

Further on, due to their very stable tri-dimensional structure and high capacity to embed fibrous powder materials or micro-porous materials, PUs were chosen as matrices for the powder materials to obtain the IR coatings [26-31] and the samples were prepared and tested accordingly.

The laboratory setup used for testing the samples 1-5 consisted of an IR radiation source represented by a calibrated black body maintained at a constant temperature of $90^{\circ} \mathrm{C}$. After applying the samples on the surface of the black body, the temperature evolution on the surface of the film was studied for 15 min using the recordings of the thermal imaging camera. The results are presented in Table 2. 
Table 2. The temperatures measured at the polymer coating surface during testing

\begin{tabular}{|c|c|c|c|c|c|}
\hline $\begin{array}{c}\text { Time } \\
(\mathrm{min})\end{array}$ & $\begin{array}{c}\text { Sample 1 } \\
\text { temperature }\left({ }^{\circ} \mathrm{C}\right)\end{array}$ & $\begin{array}{c}\text { Sample 2 } \\
\text { temperature }\left({ }^{\circ} \mathrm{C}\right)\end{array}$ & $\begin{array}{c}\text { Sample 3 } \\
\text { temperature }\left({ }^{\circ} \mathrm{C}\right)\end{array}$ & $\begin{array}{c}\text { Sample 4 } \\
\text { temperature }\left({ }^{\circ} \mathrm{C}\right)\end{array}$ & $\begin{array}{c}\text { Sample 5 } \\
\text { temperature }\left({ }^{\circ} \mathrm{C}\right)\end{array}$ \\
\hline 1 & 23.1 & 21.8 & 21 & 18.4 & 19.6 \\
\hline 1 & 34.6 & 24.6 & 24 & 32 & 27 \\
\hline 2 & 47.5 & 25.2 & 25 & 37 & 36.9 \\
\hline 3 & 54.1 & 33.1 & 32.8 & 43 & 42.5 \\
\hline 4 & 57.1 & 40.3 & 41 & 45.7 & 46 \\
\hline 5 & 60 & 45 & 44 & 47 & 49.2 \\
\hline 10 & 63.5 & 56.4 & 55.1 & 52 & 50 \\
\hline 15 & 63.5 & 57 & 57 & 51.5 & 50.8 \\
\hline
\end{tabular}

Further on, the attenuation of the thermal radiation emitted by the black body at $90^{\circ} \mathrm{C}$ due to the polymer coating application is illustrated in Figure 3.

The thermal attenuation represents the amount of heat retained by a layer in an amount of time. The heat transmitted is only proportional with the temperature difference $(\Delta t)$, while the transfer coefficient and the transfer area are constant in time and between the samples. As a result, the thermal attenuation is considered to be the ratio between the source temperature and the temperature measured on the exterior surface the polymeric coating, presented as percentage of initial temperature, as in equation (1).

$$
A=\left(T_{s}-T_{m}\right) \cdot 100 / T_{s},
$$

where $A$ is the thermal attenuation, $T_{m}$ is the temperature measured at an arbitrary time $t, T_{s}$ it the source temperature.

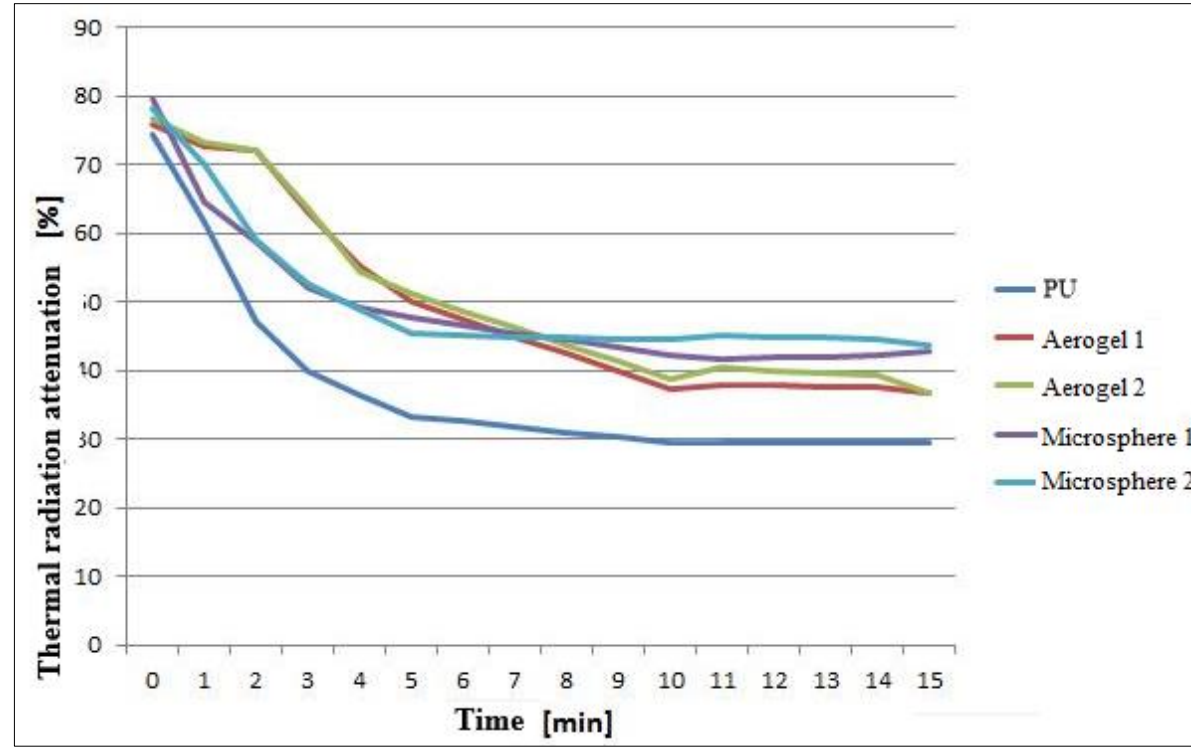

Figure 3. The attenuation of the thermal radiation versus time due to polymer coating

The polyurethane binder without additives (PU) initially retains $74 \%$ of the IR radiation, which decreases to $29 \%$ after 15 min. By adding materials with thermal-insulating properties in the polyurethane coating, the heat transfer from the inside is minimized. If, initially, the thermal attenuation is approximately the same for all the polymer coatings (75-80\%), after $15 \mathrm{~min}$ of exposure, the polymer coatings with silica-aerogel present a $37 \%$ attenuation, whereas those with glass microspheres have a $43-44 \%$ reduction of the IR radiation.

The following tests were conducted only on a variety of $\mathrm{K} 1$ glass microspheres, as these materials presented the highest thermal radiation attenuation capacity. The images captured by the thermal camera 
are presented in Figure 4. It is observed that a thicker coating conducts to a lower thermal signature of the object that emits IR radiation (its color appears darker, closer to the background).

The measured data were plotted to obtain the thermal evolution of each outer wall from the beginning of the heating process until the $90^{\circ} \mathrm{C}$ limit was reached (Figure 5).

Based on the experimental data, the following observations can be drawn:

- the surface of the exterior wall, for which no coating was applied, reached the maximum temperature of $63^{\circ} \mathrm{C}$ in $28 \mathrm{~min}$ and remained relatively constant, with small fluctuations due to the temperature on the heating source, of $90^{\circ} \mathrm{C}$;

- the surface of the exterior wall having an $8 \mathrm{~mm}$-thickness coating layer reached the maximum temperature of $54^{\circ} \mathrm{C}$ in $35 \mathrm{~min}$, indicating small temperature fluctuations during the experiment;

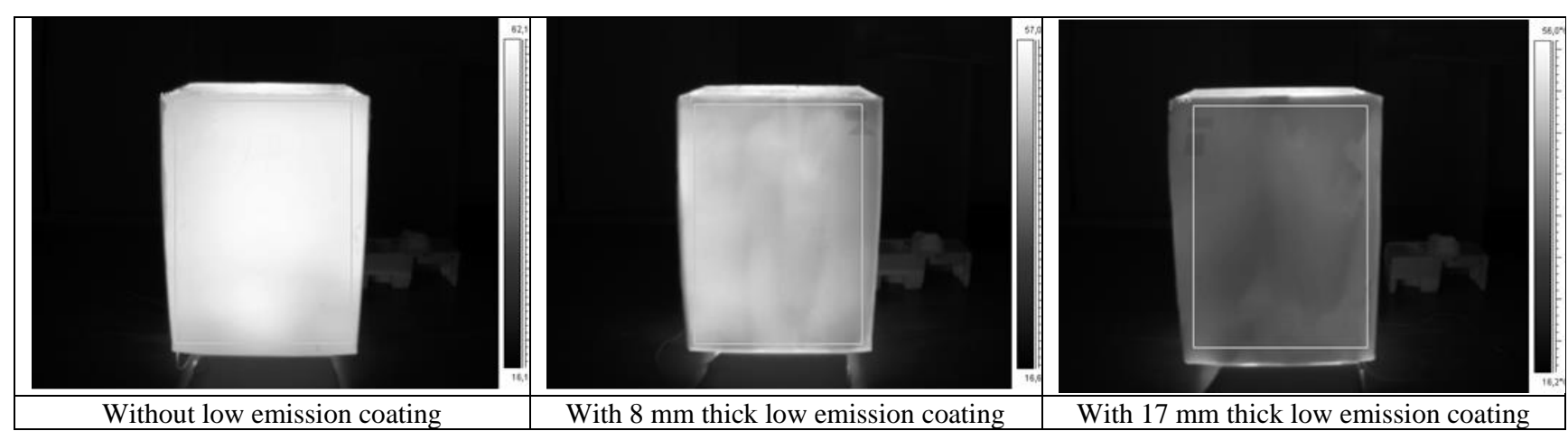

Figure 4. Testing chamber heated to $90^{\circ} \mathrm{C}$ and coated with IR camouflage of different thicknesses

- in case of the surface of the exterior wall with the $17 \mathrm{~mm}$ thickness coating layer, the heating process started with a delay, after $12 \mathrm{~min}$. in comparison with the other walls for which the temperature started to rise immediately or after $2 \mathrm{~min}$, and the maximum temperature of $40^{\circ} \mathrm{C}$ was reached in $35 \mathrm{~min}$. and remained constant during the entire heating process.

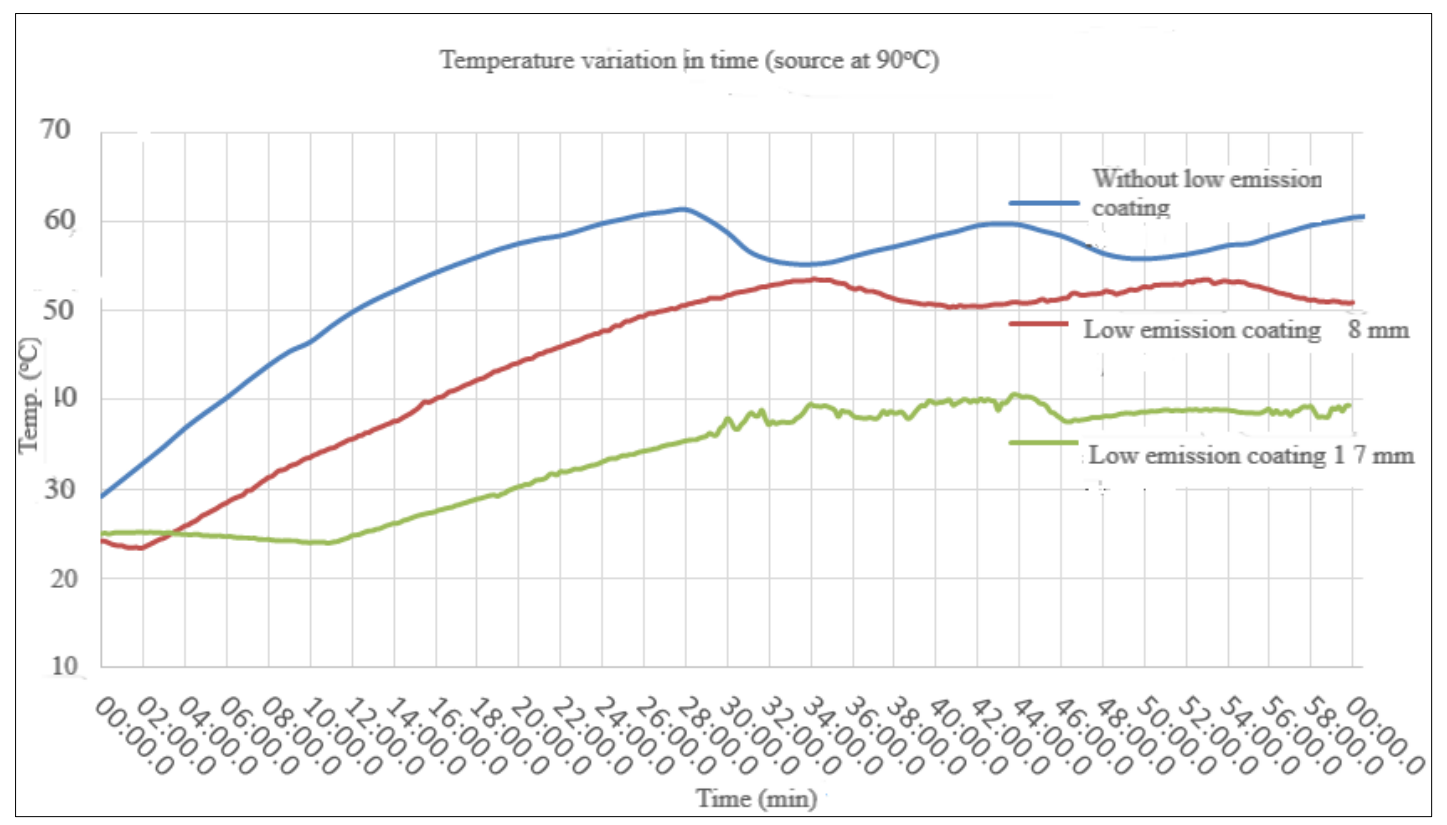

Figure 5. The thermal variation of the tested chamber versus time

Also, during the heating process, the temperatures of the exterior walls were measured simultaneously at two different points in time using an optical pyrometer.

The data obtained from measurement are presented in Table 3. 
Table 3. Exterior walls measured temperatures at two different moments in time, $\mathrm{t}_{1}$ (after $\left.90 \mathrm{~min}\right)$ and $\mathrm{t}_{2}($ after $180 \mathrm{~min})$

\begin{tabular}{|c|c|c|}
\hline Place of temperature measurement & Temperature $\left({ }^{\circ} \mathrm{C}\right)$ at $\mathrm{t}_{1}$ & Temperature $\left({ }^{\circ} \mathrm{C}\right)$ at $\mathrm{t}_{2}$ \\
\hline Inside the chamber (measured by the sensor) & 86.8 & 89.7 \\
\hline On the surface of the wall without coating & 61.1 & 60 \\
\hline On the surface of the wall with 8 mm coating & 46.9 & 47 \\
\hline On the surface of the wall with 17 mm coating & 33.9 & 36 \\
\hline
\end{tabular}

The results obtained from measurements indicate that a $8 \mathrm{~mm}$ IR camouflage has a thermal attenuation of ca. $45 \%$, whereas a layer of $17 \mathrm{~mm}$ thickness has a $60 \%$ thermal attenuation. These results are the same even after $3 \mathrm{~h}$ of maintaining the temperature at $90^{\circ} \mathrm{C}$ (Table 4 ).

Table 4. Temperature evolution measured at the chamber walls surface at different moments in time

\begin{tabular}{|c|c|c|c|c|c|c|}
\hline $\begin{array}{c}\text { Place of temperature } \\
\text { measurement }\end{array}$ & $\begin{array}{c}\text { Temperature } \\
\left({ }^{\circ} \mathrm{C}\right) \text { after } \\
15 \mathrm{~min}\end{array}$ & $\begin{array}{c}\text { Temperature } \\
\left({ }^{\circ} \mathrm{C}\right) \text { after } \\
30 \mathrm{~min}\end{array}$ & $\begin{array}{c}\text { Temperature } \\
\left({ }^{\circ} \mathrm{C}\right) \text { after } \\
60 \mathrm{~min}\end{array}$ & $\begin{array}{c}\text { Temperature } \\
\left({ }^{\circ} \mathrm{C}\right) \text { after } \\
90 \mathrm{~min}\end{array}$ & $\begin{array}{c}\text { Temperature } \\
\left({ }^{\circ} \mathrm{C}\right) \text { after } \\
120 \mathrm{~min}\end{array}$ & $\begin{array}{c}\text { Temperature } \\
\left({ }^{\circ} \mathrm{C}\right) \text { after } \\
180 \mathrm{~min}\end{array}$ \\
\hline $\begin{array}{c}\text { Inside the chamber } \\
\text { (sensor) }\end{array}$ & 50.1 & 76.3 & 81 & 85.1 & 86 & 90 \\
\hline $\begin{array}{c}\text { On the surface of the wall } \\
\text { without thermic layer }\end{array}$ & 45.5 & 52.5 & 55 & 59 & 59 & 59 \\
\hline $\begin{array}{c}\text { On the surface of the wall } \\
\text { with 8 mm layer }\end{array}$ & 32 & 38 & 45 & 48 & 48 & 49 \\
\hline $\begin{array}{c}\text { On the surface of the wall } \\
\text { with } 17 \text { mm layer }\end{array}$ & 24.5 & 25 & 35 & 39 & 39 & 39 \\
\hline
\end{tabular}

The efficiency of the thermal-insulation coating was also evaluated at different temperatures by heating the chamber up to $100^{\circ} \mathrm{C}$ for 10 min using a heating pump and measuring the temperature with the thermal camera every $2 \mathrm{~s}$ as it dropped for $10 \mathrm{~min}$, while the heating source was stopped. The same experiment was repeated for $150^{\circ} \mathrm{C}$. The temperatures were measured at the surface of the walls, both with and without thermal-insulator polymer coatings. The measured data are illustrated in Figure 6.

The plotted data clearly show that the temperature of the metallic surface with no coating rises immediately, in ca. 2 min and maintains constant during the heating process. When the heating stops, the temperature of the uncovered metallic wall also drops immediately.

The metallic surface coated with the $8 \mathrm{~mm}$-thick polyurethane thermal insulator composite indicates a more gradual rise in temperature, reaching a maximum after $10 \mathrm{~min}$. The cooling process was also gradual, similarly to the heating.

\section{Conclusions}

The study presents an experimental method of evaluating the possibility to develop polymeric composite coatings with IR camouflage properties by using powder materials with low density. This characteristic is determined by a high IR reflectance of the shell particles and the thermal-insulation property of the air stored inside the particles. Correspondingly, the geometry and the dimensions of the particles which form the powder material contribute to the reduction of the thermal signature of the object with IR camouflage. The polymer matrix that bonds together these materials increase the surface reflectance. Due to its low density (ca. $0.5 \mathrm{~kg} / \mathrm{m}^{3}$ ), this type of coating may represent an optimal solution for a permanent camouflage for military equipment, as it does not increase the total mass of the system on which it is applied. Also, the coating may be applied on small surfaces of the object, only where high temperatures develop, and thereby special costs are not implied. Moreover, the thickness of the film may vary with the temperatures developed. 


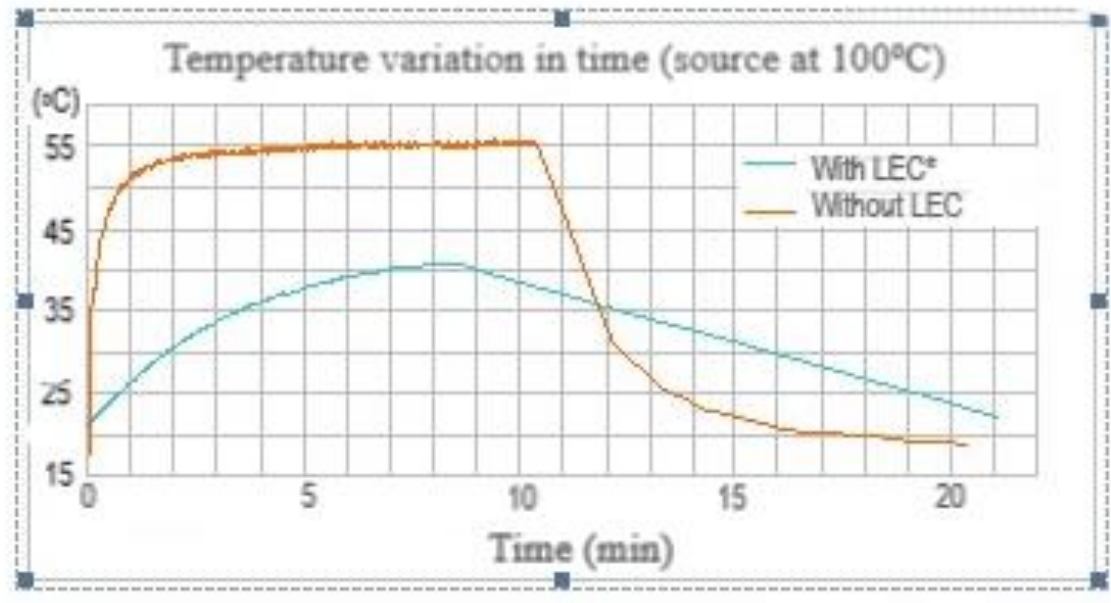

"LEC = low emission coating

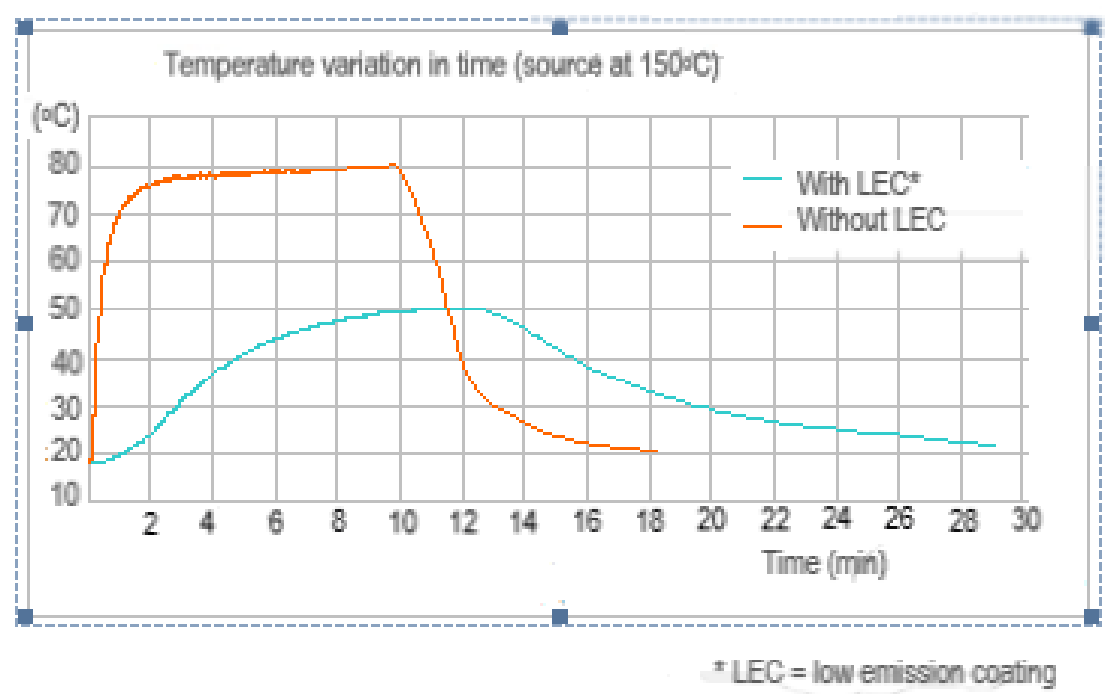

Figure 6. Variation of the heated walls temperature versus time

The polymer coating with IR camouflage properties has the capacity to decrease the temperature of the heated object down to the ambient temperature and also to maintain it constant for at least $3 \mathrm{~h}$, during which it can eliminate the risk of being detected by the thermal camera. Also, the exterior temperature of the heated object is reduced proportionally with the thickness of the thermal-insulator material. It has been demonstrated that a $20 \mathrm{~mm}$-thick layer of thermal-insulator material is sufficient for achieving an IR camouflage for heated objects.

Acknowledgements: This work was supported in part by a grant of the Romanian Ministry of Education and Research, CCCDI - UEFISCDI, project number PN-III-P2-2.1-PTE-2019-0213, within PNCDI III and in part by a grant of the Romanian Ministry of Research and Innovation, PCCDI-UEFISCDI, project no. PN-III-P1-1.2-PCCDI-2017-0395 (Research Contract No. 70PCCDI/2018) Contingency of CBRN hazards and improvement of national security resources SECURE-NET - PC5 - Passive multispectral camouflage systems based on chromogenic-polymeric organic-inorganic hybrid structures MULTICAM. 


\section{References}

1.HALLBERG, T., NIINIMÄKI-HEIKKILÄ, T., HEDBORG-KARLSSON, E., SALONEN, P.S., NILSSON, C., JÄNIS, A., Development of low emissive camouflage paint: Final report, FOI-R-1592SE, 2005.

2.MANARA, J., REIDINGER, M., RYDZEK, M., ARDUINI-SCHUSER, M., Polymer-based pigmented coatings for flexible substrates with spectrally selective characteristics to improve the thermal properties, Progr. Org. Coat., 70, 2011, 199-204.

3.BABREKAR, H.A., KULKAMI, N.V., JOG, J.P., MATHE, V.L., BHORASKAR, S.V., Influence of filler size and morphology in controlling the thermal emissivity of aluminium/polymer composites for space applications, Mater. Sci. Eng. B, 168, 2010, 40-44.

4.LIU, Z.H., BAN, G.D., YE, S.T., LIU, W.Y., LIU, N., TAO, R., Infrared emissivity properties of infrared stealth coatings prepared by water-based technologies, Opt. Mater. Express, 6(12), 2016, 37163724.

5.BRADY, R.F., LINDSAY, V.W., Principles and formulations for organic coatings with tailored infrared properties, Progr. Org. Coat., 20, 1992, 1-25.

6.LEE, H.S., STAAF, O., GHAEM, H., IR-properties of some binders for coatings industry, FOA-R00-01576-615, 2000.

7.CHENG-WU, F., HAO-SHEN, Z., MING-QING, C., Studies on organic binders with high infrared transparency, Chin. Phys. B., 18(7), 2009.

8.MAR, H.Y.B., ZIMMER, P.B., Low infrared emissivity paints comprising an oxime cured silicone binder, US Patent 4131593, 1978.

9.WAKE, L.W., BRADY, R.F., Formulating infrared coating for defence applications, Materials Research Laboratory, Research Report, 1993.

10.JONES, R.G., WILKS, E.S., VAL METANOMSKI, W., KAHOVEC, J., HESS, M., STEPTO, R., KITAYAMA, T., Compendium of polymer terminology and nomenclature, RSC Publishing, 2009.

11.AEGERTER, M.A., LEVENTIS, N., KOEBEL, M.M., Aerogel handbook, Springer Science +Business Media, 2011.

12.SACHITANADAM, M., JOSHI, S.C., Silica aerogel composites, Springer Science+Business Media Singapore, 2016.

13.SCHWAN, M., RÖßLER, M., MILOW, B., RATKE, L., From Fragile to Resilient Insulation: Synthesis and Characterization of Aramid-Honeycomb Reinforced Silica Aerogel Composite Materials, MDPI, Gels, 2(1), 2016, doi:10.3390/gels2010001.

14.JELLE, B.P., BAETENS, R., GUSTAVSEN, A., Aerogel Insulation for Building Applications, The Sol-Gel Handbook, 1385-1412, doi:10.1002/9783527670819.ch45.

15.BERARDI, U., The benefits of using aerogel-enhanced systems in building retrofits, Energy Procedia, 134, 2017, 626-635.

16.NOCETINI, K., ACHARD, P., BIWOLE, P., STIPETIC, M., Hygro-thermal properties of silica aerogel blankets dried using microwave heating for building thermal insulation, Energy and Building, 158, 2018, 14-22.

17.HE, Y.L., XIE, T., Advances of thermal conductivity models of nanoscale silica aerogel insulation material, Applied Thermal Engineering, 81, 2015, 28-50.

18.FU, Y., QU, Z., ZHOU, L., Prediction of the Effective Thermal Conductivity of Aerogel Nano-Porous Materials, Energy Procedia, 105, 2017, 4769-4775.

19.WATKINS, I.G., PRADO, M., Mechanical properties of glass microspheres, Procedia Materials Science, 8, 2015, 1057-1065.

20.REN, S., LI, X., ZHANG, X., XU, X., DONG, X., LIU, J., DU, H., GUO, A., Mechanical properties and high-temperature resistance of the hollow glass microsphere/borosilicate glass composite with different particle size, J. Alloys Compd., 722, 2017, 321-329.

21.LI, B., YUAN, J., AN, Z., ZHANG, J., Effect of microstructure and physical parameters of hollow glass microsphere on insulation performance, Mater. Lett., 65(12), 2011, 1992-1994. 
22.AMOS, S.A., YALCIN, B., Hollow glass microspheres for plastics, elastomers and adhesives compounds, $1^{\text {st }}$ Ed., William Andrew (Elsevier), 2015.

23.WANG, J., TIAN, Y., ZHANG, J, Thermal insulating epoxy composite containing sepiolite/hollow glass microspheres as binary fillers: morphology, simulation and application, Sci. Eng. Compos. Mater., 24(3), 2017, 379-386.

24.OZKUTLU, M., DILEK, C., BAYRAM, G., Effect of hollow glass microsphere density and surface modification on the mechanical and thermal properties of poly(methyl-methacrylate) syntactic foams, Compos. Struct., 202, 2018, 545-550.

25.LI, J., LUO, X., LIN, X., Preparation and characterisation of glass microsphere reinforced poly(butylene-succinate) composites, Mater. Des., 46, 2013, 902-909.

26.PRISACARIU, C., Polyurethane elastomers: from morphology to mechanical aspects, Springer, Wien New York, 2011.

27.HUYBRECHTS, J., TANGHE, L., MILIC, R., Two-component polyurethane coating compositions, US Patent 8822622B2, 2014.

28.OLSON, A., ABRAHAM, C., Two-component polyurethane coating compositions,

US Patent 20150203705A1, 2015.

29.MURRAY, P. L., Two-component polyurethane construction adhesive, US Patent 6130268A, 2000.

30.HOWARTH, G.A., Studies on surface preparation systems for polyurea protective coating of BeijingShanghai high speed railway bridge concrete beams, Surface Coatings International Part B: Coatings Transactions, 86(2), 2003, 111-118.

31. HEPBURN, C., Polyurethane Elastomers, 2nd. Ed., Elsevier Science Publishers Ltd., 1992.

Manuscript received: 21.05 .2021 